\title{
Anionic Bitumen Emulsions for Waterproofing
}

\author{
Ilvira Antonova*1[0000-0003-4079-8574], and Damir Ayupov ${ }^{10000-0002-4145-5250]}$ \\ ${ }^{1}$ Kazan State University of Architecture and Engineering, 420043 Kazan, Russia
}

\begin{abstract}
Bitumen emulsions (BE) are widely used in road construction, for building and structure waterproofing. Storage stability is one of the main $\mathrm{BE}$ requirements. They should only break on contact with the surface. The sodium oleate effect as a surfactant on the stability of anionic bitumen emulsions for waterproofing purposes has been studied. Bitumen emulsions with increased storage stability have been developed. The optimal content of sodium oleate, providing a high complex of emulsion and resulting binder properties has been determined.
\end{abstract}

Keywords. Bitumen emulsions, oleic acid, spray-applied waterproofing, liquid rubber.

\section{Introduction}

A wide range of waterproofing materials [1], including bitumen-based [2], are present on the building materials market. Torch-welded waterproofing is a widely used type of roof and foundation waterproofing with bitumen-containing materials. However, its design is associated with a number of features: open flame, roll materials lifting, personnel qualification requirements. The resulting roof coatings are of joint type, causing potential leakage. In addition, the use of torch-welded roll roofing and waterproofing materials on roofs of complex geometry and vertical surfaces, such as foundations, is associated with high labor costs. Most roof coverings do not have these disadvantages, but they contain a toxic solvent; it restricts their application range, especially in enclosed spaces. Besides, the technology of hand roof covering application is time-consuming.

In this regard, seamless spray-applied waterproofing, called «liquid rubber» becomes a relevant and promising material. It is a two-component cold spray-applied polymer-bitumen emulsion [3-4], consisting of a main component and a coagulating agent. The undoubted advantages of spray-applied waterproofing are its high chemical resistance, possible spraying on old waterproofing, no seams during application, strength, no fire hazards during operation. Also, it is solvent-free, as well as possible to use for waterproofing of surfaces with complex geometry.

However, in construction practice, this material is rarely used, as the use of bitumen emulsions in waterproofing and roofing coatings is limited by their low storage stability. Therefore, the development of effective emulsifiers and stable emulsions is still an urgent issue.

At present, most developed bitumen emulsions are used for road construction [5-6]. They provide adhesion of pavement layers, used in surface treatment and for soil reinforcement and stabilization [7]. They are cation-active [8-11]. As for road emulsions, adhesion to a mineral

*Corresponding author: antonova.ilvira@yandex.ru 
aggregate with an acidic surface is important [12]. Bitumen emulsions for waterproofing are applied mainly to surfaces with basic properties and shall demonstrate high adhesion.

Among anionic emulsions, there are compositions using industrial wastes as emulsifiers [13] - detergent production such as waste cotton seed oil (WCSO) and flotation liquid asphalt (FLA) [14-15]. But these wastes have a variable chemical composition and properties with adverse effects on the quality of bitumen emulsions.

It is generally accepted that physical or chemical modification is one of the most effective ways to obtain or improve the properties of almost any composite building materials [16-19].

\section{Materials and methods}

The preparation of stable bitumen emulsions is impossible without the use of surfactants [20-21] with required emulsifying and stabilizing properties. There are many chemical compounds that can be used to emulsify bitumen, but for technical and economic reasons, only few are widely used. A considerable part of these compounds can be used alone or in combination with one or more other compounds. They can also be modified in various ways to obtain special properties. Emulsifiers, in addition to providing emulsions with appropriate properties, should be cost-effective [22], safe and easy to use.

Many studies have established [23-24] that surfactants with the number of carbon atoms in the chain of the molecule $n_{c}=10-22$ have the best emulsifying ability.

The emulsifiers, based on oleic acid salts have a good history of application [25]. To obtain anion-active bitumen emulsions, the sodium salt of oleic acid was selected as an emulsifier in the operation, during its ionization the hydrophobic hydrocarbon group becomes a part of the negatively charged anion - -ion.

Oleic acid $\mathrm{CH}_{3}\left(\mathrm{CH}_{2}\right)_{7} \mathrm{CH}=\mathrm{CH}\left(\mathrm{CH}_{2}\right)_{7} \mathrm{COOH}$, monounsaturated monobasic fatty acid, is included in the form of lycerides in many liquid and solid fats: flaxseed, olive, cottonseed, almond, sunflower, coconut (palm) oils, etc. It is manufactured at JSC «Nefis Cosmetics» according to TU 9145-172-4731297-94 grade B-115 and is a mixture of distilled fatty acids of vegetable oils with a viscous thick-flowing state, transparent from light yellow to yellow with the following physicochemical indicators: molecular weight, $\mathrm{g} / \mathrm{mol}-282.46$, acid melting point is about $14{ }^{\circ} \mathrm{C}$, boiling point is $223{ }^{\circ} \mathrm{C}$ at $10 \mathrm{~mm} \mathrm{Hg}$, density $0.898 \mathrm{~g} / \mathrm{cm}$ at $14{ }^{\circ} \mathrm{C}$. The properties of technical oleic acid are shown in Table 1.

Table 1. Properties of technical oleic acid.

\begin{tabular}{|l|c|}
\hline \multicolumn{1}{|c|}{ Parameter } & Indicator \\
\hline Mass fraction of ash \%, max. & 0.1 \\
\hline Mass fraction of moisture, \% max. & 0.5 \\
\hline Color value, mg, iodine, max. & 70 \\
\hline Pour point, ${ }^{\circ} \mathrm{C}$ & $8-15$ \\
\hline Mass fraction of fatty acids in anhydrous product, \%, min. & 97.4 \\
\hline Mass fraction of unsaponifiable substances, $\%$ max. & 2.5 \\
\hline Acid number, $\mathrm{mg} \mathrm{KOH} / \mathrm{g}$ & $185-200$ \\
\hline Saponification number, $\mathrm{mg} \mathrm{KOH} / \mathrm{g}$ & $185-200$ \\
\hline
\end{tabular}

The sodium salt of oleic acid was produced by acid saponification with an aqueous solution of sodium hydroxide at $80{ }^{\circ} \mathrm{C}$ for $2 \mathrm{~h}$. The following chemical reaction occurs during interaction:

$$
\mathrm{C}_{17} \mathrm{H}_{33} \mathrm{COOH}+\mathrm{NaOH} \rightarrow \mathrm{C}_{17} \mathrm{H}_{33} \mathrm{COONa}+\mathrm{H}_{2} \mathrm{O} \text {. }
$$

The required amount of sodium hydroxide was calculated. The solution $\mathrm{pH}$ value should be within the range of 10-12.

To study the dependences of main technical properties of bitumen emulsions on the emulsifier concentration, the following concentrations of the sodium salt of oleic acid were 
taken: $2 \%, 2.5 \%, 3 \%, 3.5 \%$ and $4 \%$. Bituminous emulsions were obtained by grinding in a colloid mill in a 1:1 ratio of BND 70/100 bitumen produced by JSC Taif-NK and an emulsifier aqueous solution.

To determine the optimal composition, homogeneity and stability were studied for 7 and 30 days according to Standard GOST 52128-2003.

\section{Results and discussion}

The results of uniformity depending on the emulsifier concentration are shown in Fig. 1.

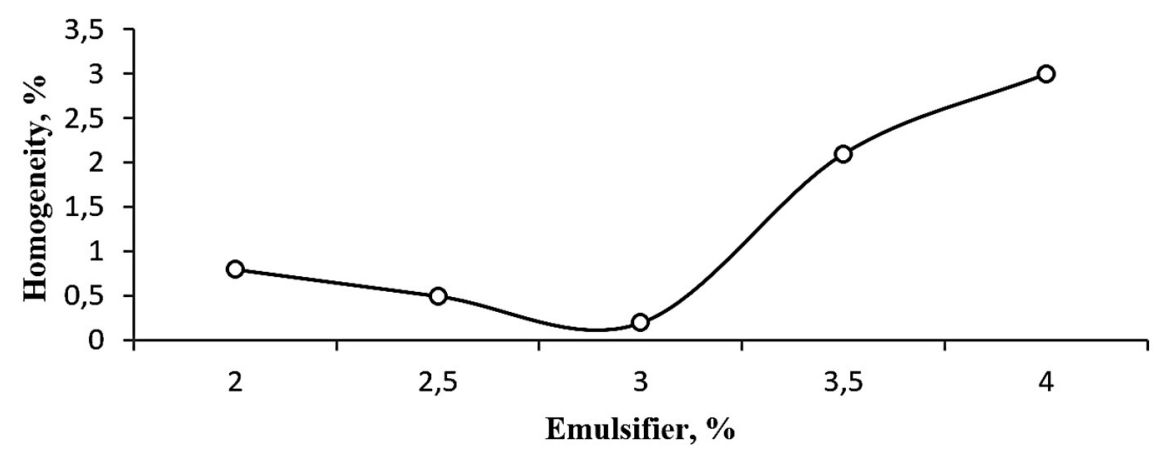

Fig. 1. Dependence of bitumen emulsion homogeneity on surfactant concentration.

The best uniformity indicator, characterized by a minimum sieve residue, is observed at $3 \%$ of emulsifier, correlating with the data on bitumen emulsion stability presented in Fig. 2-3.

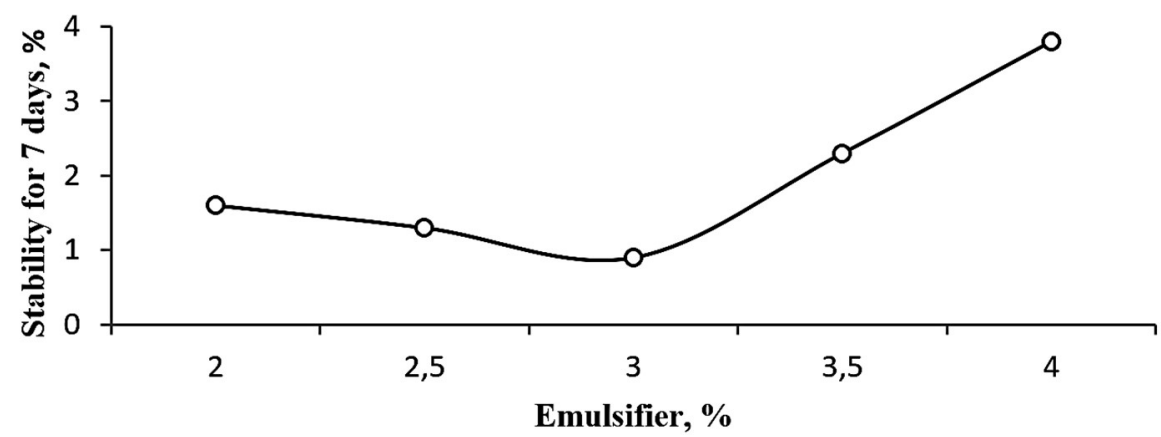

Fig. 2. Dependence of bitumen emulsion stability on surfactant concentration for seven days.

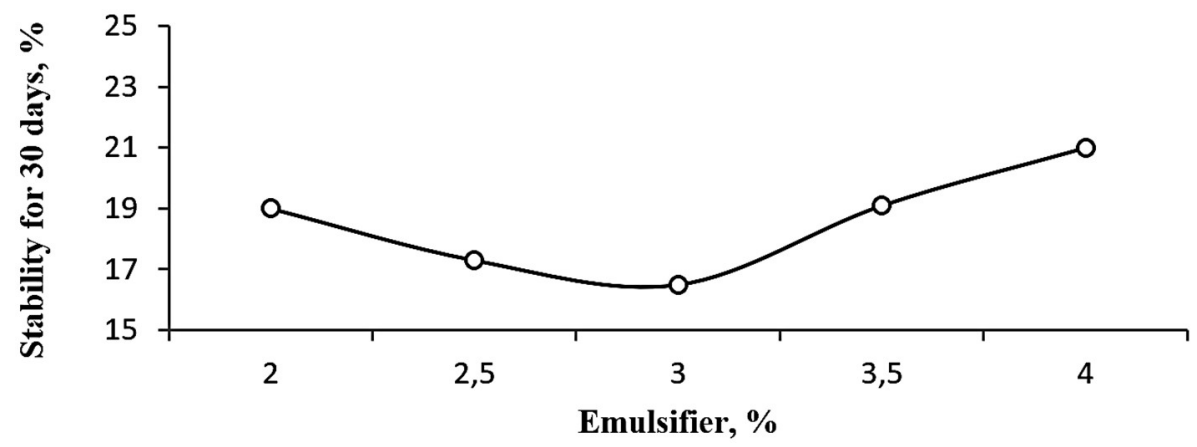

Fig. 3. Dependence of bitumen emulsion stability on surfactant concentration for thirty days. 
It is worth mentioning, that storage of anionic bitumen emulsions allows for their stratification, however, upon mixing, they should again become homogeneous. The same thing is observed for the emulsion under examination.

The viscosity of emulsions indirectly characterizes their dispersion. The dependence of the conditional viscosity of bitumen emulsions on the concentration of emulsifiers in them is shown in Fig. 4.

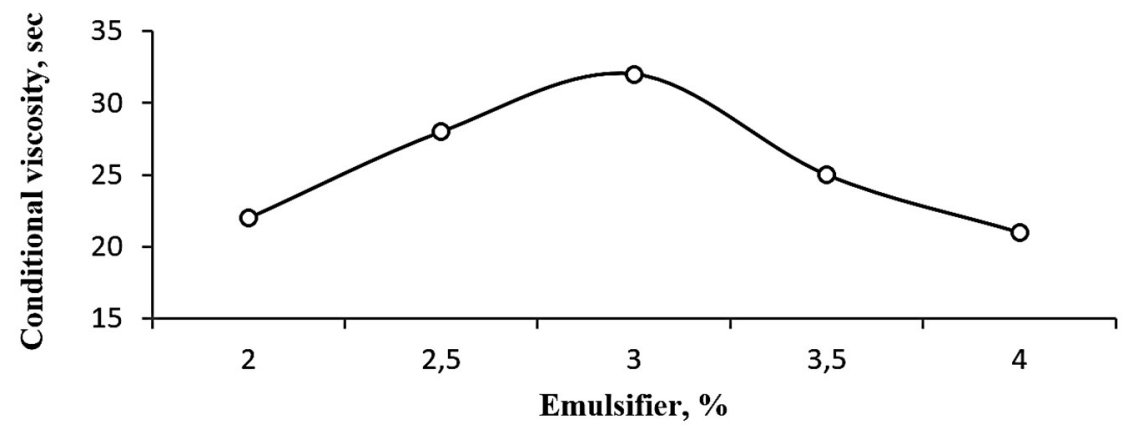

Fig. 4. Dependence of bitumen emulsion viscosity on surfactant concentration.

For this dependence, the maximum is observed at 3\% surfactant. Thus, bitumen emulsions stabilized with three percent of the developed surfactant have optimal homogeneity and stability, as well as maximum viscosity, indicating their high dispersion. The properties of the optimal emulsion composition are presented in Table 2.

Table 2. Optimal composition properties.

\begin{tabular}{|c|c|c|c|c|}
\hline BE & Homogeneity, \% & $\begin{array}{c}\text { Stability during } \\
\text { seven days, \% }\end{array}$ & $\begin{array}{c}\text { Stability during } \\
\text { thirty days, \% }\end{array}$ & $\begin{array}{c}\text { Apparent } \\
\text { viscosity, s }\end{array}$ \\
\hline $\begin{array}{c}\text { Bitumen }+3 \% \\
\text { Sodium Oleate }\end{array}$ & 0.2 & 0.9 & 16.5 & 32 \\
\hline
\end{tabular}

Later, latex can be added to the resulting emulsion to provide polymer properties to the waterproofing material [26-27]: heat resistance, flexibility at low temperatures, elasticity and resistance to deformation.

The second stage was to determine the properties of bituminous binders, isolated from emulsions by coagulation with a $5 \%$ aqueous solution of calcium chloride. The ratio of bitumen emulsion/aqueous solution of the coagulating agent was $8 / 1$.

Fig. 5 shows the dependence of binder penetration on surfactant concentration.

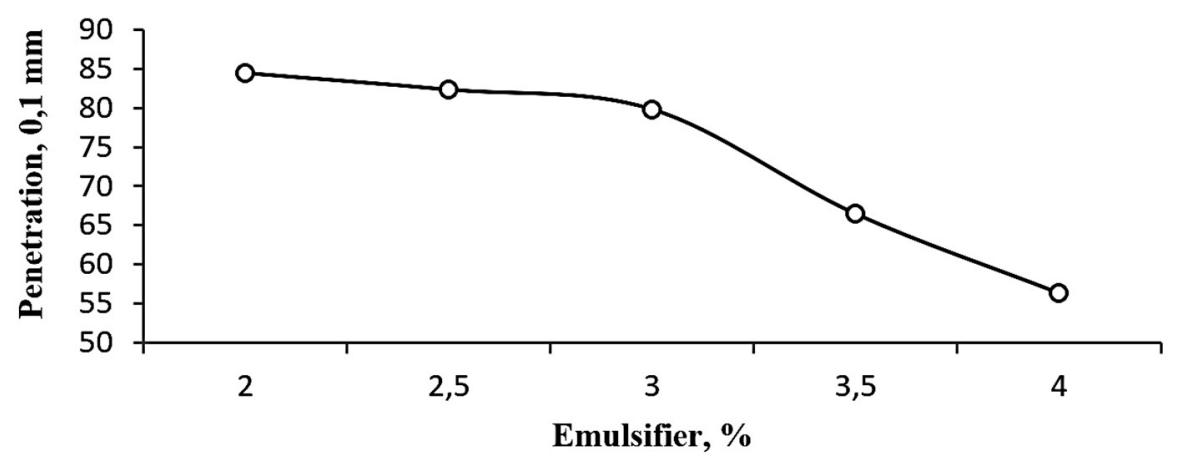

Fig. 5. Dependence of the needle penetrating depth into the bituminous binder at $25^{\circ} \mathrm{C}$ on the surfactant concentration. 
It is evident, that binder hardness increases with an increase in the emulsifier concentration. The obtained result correlates with an increase in binder heat resistance (Fig. 6).

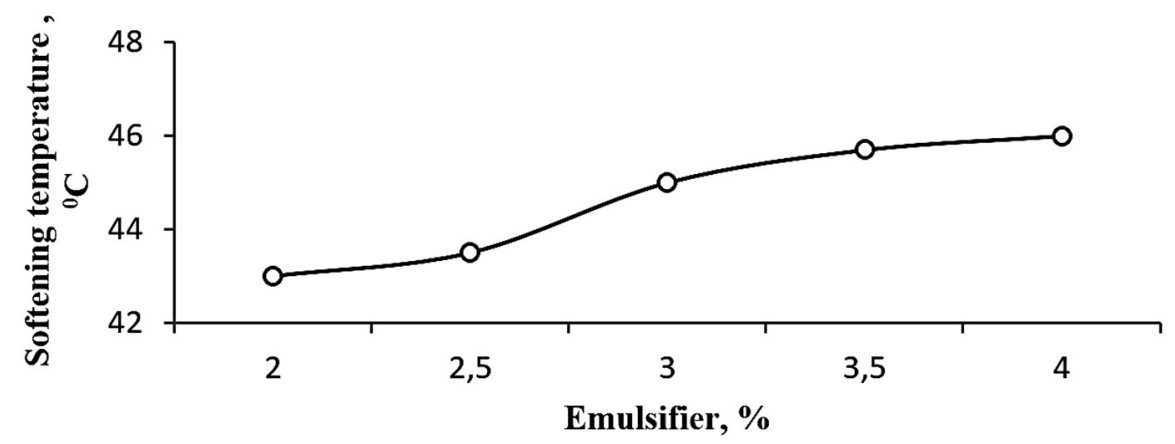

Fig. 6. Dependence of the softening temperature of the bituminous binder on the surfactant concentration.

Fig. 7 shows the dependence of bituminous binder ductility at $25{ }^{\circ} \mathrm{C}$ on the surfactant concentration.

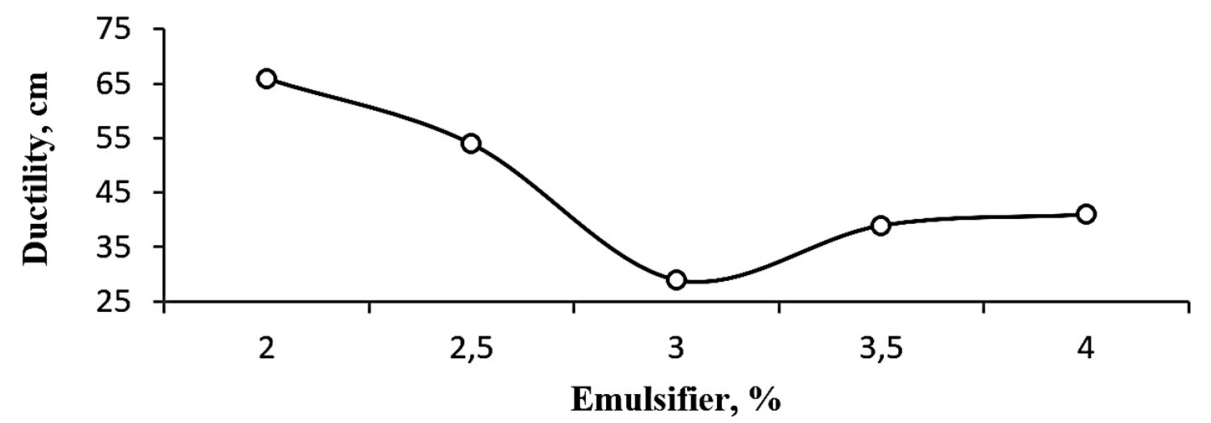

Fig. 7. Dependence of bituminous binder ductility at $25^{\circ} \mathrm{C}$ on the surfactant concentration.

This dependence is of extreme nature. Obviously, low surfactant concentrations structure the binder, while an excessive amount of surfactant plasticizes it in some degree. At the same time, as Fig. 8 shows, ductile binders are elastic which is rarely observed.

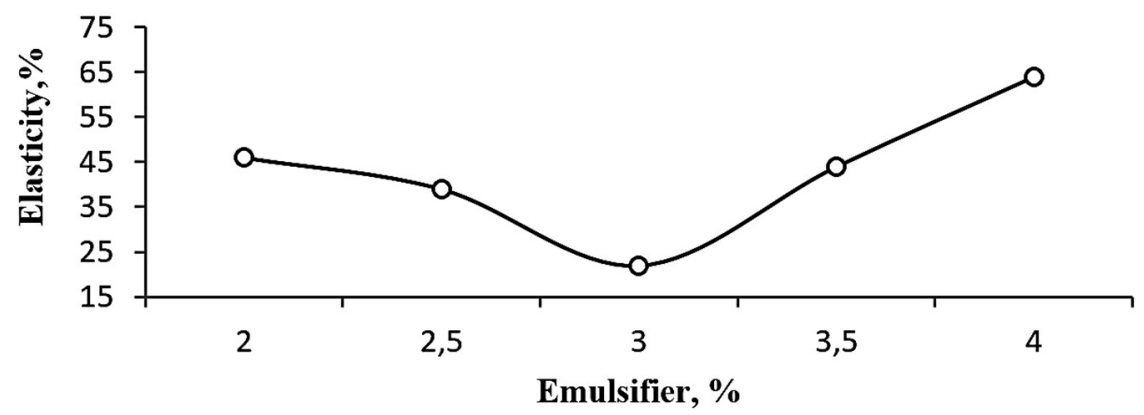

Fig. 8. Dependence of bituminous binder elasticity at $25^{\circ} \mathrm{C}$ on surfactant concentration.

Fig. 9 shows the dependence of the brittleness temperature of bituminous binders on surfactant concentration. 


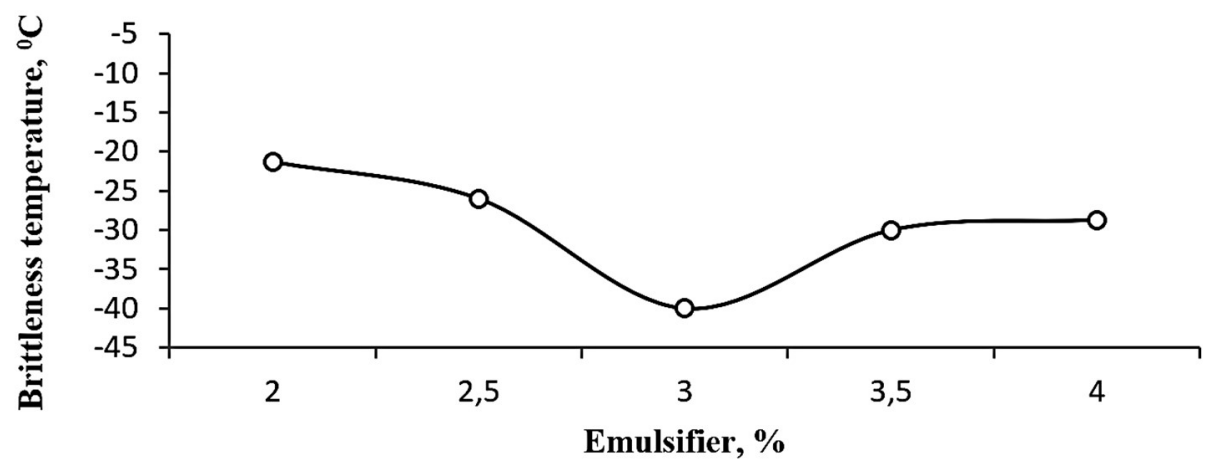

Fig. 9. Dependence of the brittleness temperature of bituminous binders on surfactant concentration.

Clearly, the developed binders, in comparison with unmodified bitumen $\left(\mathrm{T}_{\mathrm{xp}}=-15^{0} \mathrm{C}\right)$, have high low-temperature flexibility.

The analysed binders, isolated from emulsions, do not contain a polymer modifier, but the emulsifier, alkali and coagulating agent have a positive effect on their properties.

Additionally, the possible use of stearic acid as initial surfactant component for bitumen emulsions was tested. It is similar in structure and molecular weight to oleic acid, but it is saturated. The developed bitumen emulsions, when cooled, passed into a solid aggregate paraffin-like state, and it became impossible to use them for waterproofing. Therefore, it is better to use unsaturated fatty acids.

\section{Conclusion}

It was established that the developed surfactants, based on oleic acid, can be used as effective emulsifiers for producing bitumen emulsions. It was demonstrated that at 3\% surfactant emulsions have optimal homogeneity and stability, as well as viscosity, proving their high dispersion. The use of unsaturated surfactants of fatty acid series is preferable, since saturated surfactants can result in transition of emulsions to a solid aggregate state.

\section{References}

1. A.N. Dubinyak, I.I. Ovchinnikov. Rus. J of Trans. Eng. 2 (7), (2020).

2. A. Rupal, S.K. Sharma, G.D. Tyagi. Mater. Today: Proceed. 27 (1), 467-474 (2020). DOI: 10.1016/j.matpr.2019.11.27.

3. D.D. Khamidulina, S.S. Podushkin. Actual Problems of Modern Science, Technology and Education (Akt. probl. sovrem. nauki, tekhn. i obr.) 1, 244-247 (2017).

4. K.V. Avdeeva, B.S. Yushkov. Ecology and Scientific and Technical Progress (Ekologiya i nauchn.-tekhn.progress), Urban Science 2, 17-29 (2013).

5. M.A. Khasawneh, S.K. Alyaseen. Materials Today: Proceedings 33, 1752-1757 (2020). DOI: $10.1016 /$ j.matpr.2020.04.870.

6. C. Lopez, A. Gonzalez, G. Thenoux, G. Sandoval, J. Marcobal. J. of Cleaner Prod. 209, 1461-1472 (2019). DOI: 10.1016/j.jclepro.2018.11.138.

7. G. Mazurek, M. Iwański, P. Buczyńsk, R. Horodecka. Arch. of Civil and Mech. Eng., 21 (2), (2021).

8. A. Yuliestyana, M. García-Moralesa, E. Morenob, V. Carrerab, P. Partala. Mat. and Des. 131, 242-251 (2017). DOI: 10.1016/j.matdes.2017.06.024.

9. M. Zalnezhad, E. Hesami. J of Traffic and Trans. Eng. (English Edition) 7, 215-226 (2020). DOI: 10.1016/j.jtte.2018.12.005. 
10. T. Alenezi, J. Norambuena-Contreras, A. Dawson. Garcia Alvaro. J of Cleaner Prod. 212 , 37-45 (2019). DOI: 10.1016/j.jclepro.2018.11.297.

11. M. Dareyni, A.M. Moghaddam. Constr. and Build. Mat. 198, 226-236 (2019). DOI: 10.1016/j.conbuildmat.2018.11.186.

12. S.El Asjadi, Q.A. Nederpel, I.M. Cotiuga, S.J. Picken, N.A.M. Besseling, E. Mendes, B.J. Lommerts. Colloids and Surf. A: Physicochem. and Eng. Asp. 546, 326-333 (2018). DOI: 10.1016/j.colsurfa.2018.02.035.

13. M.N. Razali, S.N. Ezatie Mohd Isa, N.A. Md Salehan, M. Musa, M.A. Abd Aziz, A.H. Nour, R.M. Yunus. J. Chem. 20 (1), 96-104 (2020). DOI: 10.22146/ijc.40888.

14. A.V. Murafa, L.S. Sibgatullina, D.B. Makarov, V.G. Khozin. Stroitel'nye Materialy, 22-25 (2005).

15. R.L. Nogueira, J.B. Soares, S. de A. Soares. Constr. and Build. Mat. 223, 1145-1153 (2019). DOI: 10.1016/j.conbuildmat.2019.06.128.

16. E.A. Vdovin, V.F. Stroganov. IOP Conf. Ser.: Mater Scie Eng. 832, (2020).

17. R.R. Galeev, L.A. Abdrakhmanova, R.K Nizamov. Solid State Phenomena 276, (2018). DOI: 10.4028/www.scientific.net/SSP.276.223.

18. R.Kh. Mukhametrakhimov, A.R. Galautdinov, A.M. Garafiev. Izvestiya KGASU 4 (54), (2020).

19. B.R. Chutaev, R.K. Nizamov, L.A. Abdrakhmanova. Izvestiya KGASU 2 (48), (2019).

20. A. Abdullin, E. Emelyanycheva. J of Chem. Techn. and Met. 55 (1), 73-80 (2020).

21. R. Mercado, L. Fuentes Pumarejo. Constr. and Build. Mat. 123, 162-173 (2016). DOI: 10.1016/j.conbuildmat.2016.06.129.

22. M. Gonçalves, J. Silvestre, J. Brito, R. Gomes. J of Build. Eng. 24, (2019).

23. Guangsheng Cao, Tong Du, Yujie Bai, Tingyuan Yang, Jize Zuo. Sci. and Eng. 196, (2021).

24. S. Ghosh, A. Ray, N. Pramanik. Bioph. Chem. 265, (2020). DOI: 10.1016/j.bpc.2020.106429.

25. A.A. Noskova, A.O. Piven, D.Yu. Sladkov. Synthesis of Emulsifiers Based on Oleic Acid, Problems of Geology and Subsoil Development: Tomsk proceedings of $23^{\text {rd }}$ international symposium named after academician M.A. Usov for students and young scientists, dedicated to the $120^{\text {th }}$ anniversary of the birth of academician K.I. Satpayev 2, 349-351 (2019).

26. N.H. Daniel et al. IOP Conf. Ser.: Mater. Sci. Eng. 527, (2019).

27. A. Usman, N. Izzaty, R. Ibrahim, M.H. Sutanto, S. Sunarjono. Intern. J of Innov. Techn. and Expl. Eng. 9 (1), 4435-4440 (2019). DOI: 10.35940/ijitee.A5257.119119. 